L. Püllen', M.-O. Grimm², V. Grünwald ${ }^{1,3}$

${ }^{1}$ Klinik für Urologie, Universitätsklinikum Essen, Essen, Deutschland

${ }^{2}$ Klinik für Urologie, Universitätsklinikum Jena, Jena, Deutschland

${ }^{3}$ Westdeutsches Tumorzentrum Essen, Innere Klinik (Tumorforschung), Klinik für Urologie, Universitätsklinikum

Essen, Essen, Deutschland

\title{
Erratum zu: Update Nierenzellkarzinom
}

\section{Erratum zu:}

best practice onkologie 2020

https://doi.org/10.1007/s11654-020-00210-x

Im Original-Beitrag ist Tab. 4 leider fehlerhaft. Nachfolgend die Tabelle mit der korrekten Therapiesequenz.

\section{Korrespondenzadresse}

\section{Dr. L. Püllen}

Klinik für Urologie,

Universitätsklinikum Essen

Hufelandstraße 55, 45147 Essen, Deutschland

lukas.puellen@uk-essen.de
Tab. 4 Therapiesequenz in Abhängigkeit vom Risikoprofil gemäß IMDC (The International Metastatic Renal Cell Carcinoma Database Consortium)

\begin{tabular}{|c|c|c|}
\hline & Erstlinientherapie & $\begin{array}{l}\text { Zweitlinien- } \\
\text { therapieoptionen }\end{array}$ \\
\hline \multirow{7}{*}{$\begin{array}{l}\text { Günstiges } \\
\text { Risikoprofil }\end{array}$} & Pembrolizumab/Axitinib & \multirow[t]{7}{*}{-} \\
\hline & Avelumab/Axitinib & \\
\hline & Alternativ: & \\
\hline & Bevacizumab + Interferon $a$ & \\
\hline & Sunitinib & \\
\hline & Pazopanib & \\
\hline & Tivozanib & \\
\hline \multirow{4}{*}{$\begin{array}{l}\text { Intermediäres } \\
\text { Risikoprofil }\end{array}$} & Ipilimumab/Nivolumab & \multirow{4}{*}{$\begin{array}{l}\text { Cabozantinib oder } \\
\text { anderer TKI } \\
\text { Alternativ: Lenvati- } \\
\text { nib + Everolimus } \\
\text { Wenn nicht möglich } \\
\text { Everolimus-Mono- } \\
\text { therapie }\end{array}$} \\
\hline & Pembrolizumab/Axitinib & \\
\hline & Avelumab/Axitinib & \\
\hline & $\begin{array}{l}\text { Wenn nicht möglich: } \\
\text { Cabozantinib }\end{array}$ & \\
\hline \multirow{5}{*}{$\begin{array}{l}\text { Ungünstiges } \\
\text { Risikoprofil }\end{array}$} & Ipilimumab/Nivolumab & \multirow[t]{5}{*}{-} \\
\hline & Pembrolizumab/Axitinib & \\
\hline & Avelumab/Axitinib & \\
\hline & $\begin{array}{l}\text { Wenn nicht möglich: } \\
\text { Cabozantinib }\end{array}$ & \\
\hline & Alternativ: Temsirolimus & \\
\hline
\end{tabular}

Die Online-Version des Originalartikels ist unter https://doi.org/10.1007/ s11654-020-00210-x zu finden.

best practice onkologie 2020 • 15 (6): 276

https://doi.org/10.1007/s11654-020-00228-1

Online publiziert: 3. Juni 2020

๑) Springer Medizin Verlag GmbH, ein Teil von Springer Nature 2020 